\title{
An Investigation into Pedagogical Content Knowledge (PCK): Teachers' Views on Knowledge
}

\author{
Rui Feng Lyu \\ School of Foreign Studies, Guangdong University of Finance and Economics, Haizhu, Guangzhou, PR China
}

\section{Email address:}

20689016@qq.com

\section{To cite this article:}

Rui Feng Lyu. An Investigation into Pedagogical Content Knowledge (PCK): Teachers' Views on Knowledge. Teacher Education and Curriculum Studies. Vol. 6, No. 2, 2021, pp. 41-50. doi: 10.11648/j.tecs.20210602.11

Received: April 2, 2021; Accepted: April 23, 2021; Published: May 8, 2021

\begin{abstract}
Pedagogical Content Knowledge (PCK) has been given a lot of attention in the academic field in recent years, inparticular in the field of teacher cognition and teacher knowledge. This research aimed to investigate the views on language (regarded as one aspect of PCK) shown in the practices of six Chinese in-service teachers teaching College English at two universities in the south of China by using a qualitative multiple case study approach. The existing literature guided the current research, which investigated teachers' views on knowledge to guide language teacher education and development in mainland China. The results of the data analysis in this study revealed that the participant teachers were generally experienced in their use of declarative knowledge, but possibly unskilled in their use of strategic knowledge. To summarize, views on knowledge encompasses teachers' creative ways of thinking and their personal understanding of the discipline of teaching. It is the teachers' ability to endow declarative knowledge with personal significance. Views on knowledge include teachers' personal wisdom that transforms procedural knowledge into strategic knowledge (the ability to solve problems in classroom teaching practice). It entails teachers' constant updating and development of their personal pedagogical knowledge in the teaching practice of particular subject matter.
\end{abstract}

Keywords: PCK, Teachers' Views on Knowledge, Teacher Education and Development, Teacher Knowledge

\section{Introduction}

\subsection{PCK Research}

The concept of pedagogical content knowledge (PCK, a combination of pedagogical knowledge and content knowledge) proposed by Shulman [31], was described as teachers' understanding of "the most useful forms of representation of the most powerful analogies, illustrations, examples, explanations, and demonstrations: the ways of representing and formulating the subject" (p.9). It has provided a crucial way for scholars to conduct deep study into the relationship between teachers and teaching. A number of empirical studies have been conducted in various contexts to understand teachers' PCK and to make recommendations for related teacher education [11]. PCK has also proved helpful in research about teacher cognition, such as studies on teachers' thinking processes [39] and about the practical characteristics of the teacher knowledge base [36]. This line of research has also defined the concept of pedagogical content competence
(PCC) [40].

Based on all this research, PCK is currently seen as a potential theoretical framework for understanding teachers' abilities relevant to their teaching practice [10]. PCK has become a framework for research on teacher knowledge and has attracted many investigators in this field since Shulman's introduction of the term. Shulman's idea of PCK has been consolidated based on the existing empirical evidence [11]. Ball, Thames, and Phelps [2] summarized three categories of empirical studies about PCK in the current literature. These categories have examined how teachers' views on their subjects impact their teaching methods; the need for teachers to understand how well their students master subject matter knowledge in order to teach effectively; and how teachers' lack of subject matter knowledge influences the formation of PCK.

Meanwhile, Ball also found that a quarter of the current literature about PCK has focused on science education; the 
current study investigated PCK in English as a foreign language (EFL) teaching as a step towards addressing this imbalance. Moreover, no empirical study has yet been conducted to clarify how pedagogical knowledge (a teacher's knowledge of teaching: how to deliver knowledge to his or her students they teach) and content knowledge (a teacher's knowledge of a particular subject matter, in this article, English, to be more specific, college English related courses) are interwoven to form PCK evidenced in classroom teachers' views on knowledge; this is the main focus of the current research (How teachers' views on knowledge contribute to PCK?). As it has become acknowledged that each subject has an educational dimension that is closely related to its content, there has been a shift from general to specific approaches in teacher education. Thus, this study's investigation of College English teachers' PCK can add new information to the existing literature on PCK in EFL teaching.

The current empirical study investigated and re-conceptualized university teachers' Pedagogical Content Knowledge, particularly, their views on knowledge, in order to understand teachers as reflective practitioners (Burns, 2010). The following general question guided the whole structure of the present study: What are the characteristics of Chinese in-service College English teachers' Pedagogical Content Knowledge in terms of their views on knowledge?

\subsection{Context of This Study}

In the higher education sector in China, College English is a required basic course for undergraduate non-English major students in colleges as well as universities, and it is an integral part of higher learning. This study analyzed College English teachers who were teachers of non-English majors rather than teachers of English majors because, in mainland China, the number of English majors in tertiary education is much smaller than that of non-English majors. This means that teachers of non-English majors are responsible for the teaching of many more students than teachers of English majors.

In the university where I have been teaching, every teacher is evaluated by their students at the end of each semester on the quality of their classroom teaching practice. Surprisingly, I found from the results of a few years past (2009-2012) that there was a large gap between the highest and the lowest scores. I became curious about the reasons for the gap, which must include factors related to both the teachers and the students, and I decided to search for the reasons for this gap from the teachers' perspective. As I read more literature on the teacher knowledge base [43], I began to realize that the teachers' Pedagogical Content Knowledge (PCK) might impact the effectiveness of their classroom teaching practice, leading to different achievements in students' learning [6]. That seemed like a plausible key reason for students' different preferences for their teachers.

With this sense of curiosity, and permission from my department, I selected 3 teachers (participants of this study from Finance University and the other 3 were from Teachers' University, pseudonyms were used here) with greatly differing scores from the Department of Foreign Languages to observe their daily classroom teaching. I conducted classroom teaching observations in accordance with the techniques advocated by Louis, Lawrence, and Keith [20]. These observations lasted for one semester. They revealed that there were wide variations in terms of the observed teachers' PCK as reflected in the factors mentioned in Han's study [15]: the teachers' attitudes, lesson plans, classroom activities, classroom atmosphere, classroom management, and classroom interactions.

\section{Literature Review: Teachers' Views on Knowledge}

Richards [26] explained the essence of teaching as a teacher's interactive decisions during constantly changing classroom activities that consist of various elements. Language teachers obtain subject matter-related knowledge including knowledge of language, language acquisition, language learning, language learners, teaching methods, language tests, and the language learning environment. This knowledge informs the teachers' personal pedagogical reasoning and decisions, which in turn impacts the whole teaching process.

The focus of teacher knowledge research has shifted from investigating generalizable knowledge to looking at more personal knowledge in practice [31]. Teachers blend content knowledge, pedagogical knowledge, teaching theory, and practical teaching knowledge to form their own understanding of the relationships between complicated classroom environmental factors. This understanding can be reflected during the classroom decision-making process. Thus, in essence, Pedagogical Content Knowledge (PCK) is a kind of knowledge-in-action, a kind of special wisdom that is used to promote students' progress effectively during classroom teaching [18].

All decisions made by teachers in their classroom teaching processes can be attributed to their personal understanding of classroom teaching based on the particular circumstances involved in their teaching context. Therefore, when a teacher's classroom teaching is described and analyzed, their personal understanding of teaching becomes explicit. The types of decisions that teachers tend to make based on this understanding form gradually during the process of teacher education and develop extensively during professional practice [35].

This reasoning and decision-making not only demonstrate the characteristics of teachers' thinking during their teaching but also reflect the dynamic process that takes place during actual teaching activities. During classroom teaching, teachers should clearly recognize a variety of constantly changing factors and adjust their own teaching objectives, content, methods, process, and strategies in accordance with students' different performances. It is through the experience of making 
these decisions and adjustments that teachers eventually integrate all subject matter knowledge into their comprehensive competence to make teaching decisions: this is called Pedagogical Content Competence (PCC), and is one of the most important parts of teachers' individual professional knowledge [40].

Teachers are wise at decision-making in the classroom: for example, they make decisions in accordance with their cognition, understanding, and experience of classroom teaching. However, these decisions do not clearly originate from any particular pedagogical or teaching theory. Instead, teachers integrate their knowledge and experience of all aspects of classroom teaching. Teachers make decisions according to their experience or wisdom: this decision-making is one important kind of PCK and, therefore, definitely involves teachers' views on knowledge [15].

Teachers can view knowledge in three different ways: declarative, procedural, or strategic [25]. These views on knowledge reflect different correlations between teacher knowledge, classroom teaching, and teacher cognition. Table 1 categorizes different aspects of PCK and links them to different views on knowledge.

Table 1. Teacher Knowledge.

\begin{tabular}{lll}
\hline Knowledge Categories [15] & Views of Knowledge [25] & Knowledge Content \\
\hline \multirow{2}{*}{ Content Knowledge } & Declarative & Subject matter knowledge [26] \\
& Procedural & Communication skills [26] \\
Theory Knowledge & Declarative & Basic theory \\
& Strategic, also known as knowing-in-action [29] & Personal theory [26] \\
& Declarative & English teaching methodology \\
Practical Knowledge & Procedural & Lesson plan design skills \\
& Procedural & Teaching skills [26] \\
& Strategic & Pedagogical reasoning and decision-making [26] \\
Education Knowledge & Declarative & Contextual knowledge [26] \\
& Declarative & Knowledge of educational ends, purposes, values [32] \\
\hline
\end{tabular}

Pi's [25] three views on knowledge are summarized below:

\subsection{Declarative View}

Declarative knowledge is knowledge that can be expressed using language, such as linguistic cultural knowledge (which falls in the content knowledge category), basic theory knowledge (which falls in the theory knowledge category), and teaching knowledge (which falls in the practical knowledge category) [41]. In English language teaching, all this declarative knowledge is related to the structure of the English language (pronunciation, grammar, and vocabulary), the function of the English language, cultural topics related to English, and English teaching principles, approaches, and techniques that can both be described using language and also be widely applied through textbooks and courses. Thus, declarative knowledge can be accurately and easily understood. It is a kind of common knowledge used for communication.

\subsection{Procedural View}

Procedural knowledge helps people accomplish things through the use of rules and concepts [17]. It is comprised of communication skills (which fall into the content knowledge category, for example, knowledge of the linguistic and pragmatic rules people use to communicate), and design and management skills (which fall in the practical knowledge category, for example, the English teaching methods that teachers use to plan and manage their classrooms). The reason why these are regarded as practical teaching skills is that they are different from the key functions of narrative knowledge (such as memorization, understanding, analysis, comparison, criticism, and consultation). These skills are mainly acquired and applied through real-life practice. The knowledge applier's individual awareness or innovation skills are involved in the entire process. Thus, the application of procedural knowledge is more personalized than that of narrative knowledge.

\subsection{Strategic View}

A teacher's strategic knowledge is knowledge that they can use to control or resolve specific issues in their classroom teaching practice. Teaching is, to a large extent, determined by the interactive strategies teachers use during classroom teaching, as the teacher adjusts their teaching content, methods, and strategies to stimulate students' learning potential in accordance with students' actual responses to unexpected issues [26, 36, 38]. Strategic knowledge is not only the simple application of rules and concepts; it is also inspired by the teacher's personal practical experience. It can be regarded as intuition or innovative thought called up by particular situations. It is a blend of the teacher's various types of knowledge, experience, and wisdom. Strategic knowledge is more personal than procedural knowledge because a teacher decides to use a specific strategy to meet students' needs in a particular classroom context. It is strategic knowledge that teachers strive to master in order to reach an ideal level of classroom teaching skill, that is, a level at which the teachers can speak without considering which words or sentences they should use and can make themselves understood without any assistance [34]. It is a knowledge structure in teachers' minds that can be flexibly and directly used to make decisions in classroom teaching. Even if teachers fail to recognize the knowledge that they use in 
their teaching practices, they can still use this knowledge directly and it is a part of their knowledge structure.

The more directly a kind of knowledge affects a teacher's teaching practice behavior, the more centrally it is positioned in the teacher's PCK [19]. For example, strategic knowledge is the most central to English teachers' PCK because it determines their actual process of English teaching most directly. This is the main reason why teaching analysis needs to involve a teacher's classroom decision-making.

\section{Methodology: Research Design}

Richards [26] argued that, when foreign language teachers study classroom teaching, they should be instructed using three processes. The first is the micro-approach, which can be used to depict specific processes used in classroom teaching. Using this approach, teachers can conduct deep analysis of the specific features of classroom teaching; these may reveal insights into larger objectives of teachers' development, such as their professional skills and approaches to teaching. The second process is the macro-approach, which is associated with the theory of classroom teaching: for instance, teachers can explore the characteristics of classroom teaching through generic summary and deduction in accordance with the non-intuitive and non-quantifiable classroom teaching process. The third process is the conceptualization of teachers' professional development.

The processes Richards [26] described were used to guide the design of this study. It was appropriate to follow this procedure since the ultimate purpose of this study was to conceptualize Chinese in-service College English teachers' PCK (views on knowledge) to inform their continuing education and development by describing their specific classroom teaching procedures. The following section will outline how this research followed this procedure in more detail.

First, participatory classroom observation of each participant teacher's College English classroom teaching was carried out. This classroom observation was the basis for later description of each teacher's specific teaching process, which will be reported in the section on data analysis. Next, the teaching features of the participants were summarized, so as to deduce their PCK (views on knowledge) structures, as explained in the discussion section. Lastly, suggestions were made for College English language teacher education and development in China.

When choosing a research approach, Duff [8] has advocated that research methods should be consonant with research questions. The research question that guided this study (What are the characteristics of Chinese in-service College English teachers' PCK in terms of their views on knowledge?) marked it as an in-depth exploration of teachers' PCK (views on knowledge) carried out through analyzing their classroom teaching practice. A qualitative approach was appropriate for this research because qualitative research can describe participants' contexts, practices, behaviors, actions, thoughts, attitudes, ideas, opinions, understanding, and beliefs in detail [1]. In this study, these were considered as they related to participants' classroom teaching in the analysis of the participants' PCK (views on knowledge). A qualitative approach was also appropriate because it can help illuminate participants' experience as it is lived, felt, and undergone in its natural setting [23].

This research is descriptive as it was designed to summarize Chinese in-service College English teachers' PCK (views on knowledge) systematically, by observing their classroom teaching overall and describing their classroom teaching processes factually. Descriptive research can be conducted using case studies with interviews and observations as data collection methods [30]. Therefore, this study was case study-oriented.

Scholars have stressed the benefits of using case studies in academic research. For example, Merriam [24] said that qualitative case study approaches address broad, flexible, and open-ended research questions. In the case of this study, the research question (What are the characteristics of Chinese in-service College English teachers' PCK in terms of their views on knowledge?) was broad and general so that it could capture as many individual features related the participating teachers' classroom teaching as possible. This allowed the study to paint a detailed picture of the characteristics of teachers' PCK (views on knowledge).

Moreover, Grossman [13] argued that the use of case study, overall, helps the researcher "gather in-depth data on the content and organization of an individual's knowledge." In this research, the case study method was able to help the researcher gather in-depth data from various sources on the content and organization of every participant teacher's PCK (views on knowledge). Case studies have also been employed by other scholars to investigate teacher knowledge [9], PCK [14], the relationship between the role of experience and professional knowledge development [28], and the relationship between expertise and knowledge in teaching [36].

Case study has been defined as a "bounded system" (Smith as cited in Merriam, [22]), "a single entity, a unit around which there are boundaries" [22]). In this study, all the participant teachers certainly had their own boundaries due to their individual differences; regardless of the selection criteria, they represented themselves and although they can, to some extent, reflect a number of teachers with similar backgrounds and experiences, it is impossible for them to stand for all teachers.

Furthermore, this research employed a multiple-case study approach because this approach can "show different perspectives of the issue" [5]. Different cases were compared and contrasted in order to understand teachers' PCK (views on knowledge) and classroom practices better. In this study, "an integrated system" [33] was formed by using cases of teachers with different characteristics to cast light on their PCK (views on knowledge) as a whole. A case study has three features: it is particularistic, descriptive, and heuristic [22]. All of these features are reflected in this study. 


\subsection{Particularistic}

In the current research, six particular Chinese in-service College English teacher participants were selected as representative samples in the investigation of PCK (views on knowledge). The literature review found that being particularistic is one of the major characteristics of PCK (views on knowledge). Therefore, the conclusions drawn from this study are difficult to generalize to a larger population.

\subsection{Descriptive}

In this study, a large amount of description was used during the data analysis to understand the participants' PCK in terms of the types of knowledge (declarative, procedural, or strategic) most prevalent in their classroom teaching. Comparisons and contrasts were made between different teachers so that the similarities and differences in the participants' PCK (views on knowledge) could be presented clearly, vividly, and convincingly.

\subsection{Heuristic}

Generally, the ultimate purpose of all the academic research is to gain heuristics at different levels. This research is no exception. For instance, this research selected particular teachers and described their PCK (views on knowledge) so as to generate implications for teacher education and development (in particular, for Chinese in-service College English teachers).

To summarize, in this study, I used multiple research methods to conduct an in-depth exploration of teachers' PCK (views on knowledge). Table 2 illustrates the entire data collection procedure, including specific phases and methods.

Table 2. Sources of Data.

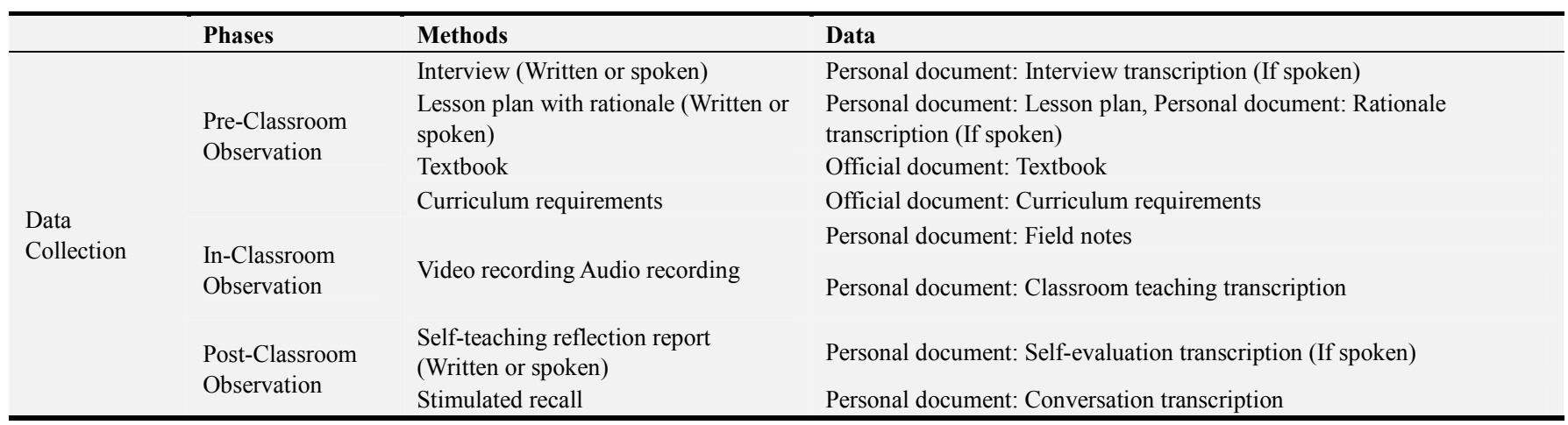

Table 3. Participants : Participant Teachers' Particulars.

\begin{tabular}{|c|c|c|c|c|c|c|}
\hline & \multicolumn{3}{|c|}{ Finance University (FU) } & \multicolumn{3}{|c|}{ Teachers University (TU) } \\
\hline & Ding (FU1) & Deng (FU2) & Yang (FU3) & Wei (TU1) & Liu (TU2) & Xie (TU3) \\
\hline Gender & $\mathrm{F}$ & $\mathrm{F}$ & $\mathrm{F}$ & $\mathrm{F}$ & M & $\mathrm{F}$ \\
\hline DOB & 1980 & 1980 & 1977 & 1977 & 1979 & 1973 \\
\hline Position & Instructor & Instructor & Instructor & Instructor & Associate Instructor & Associate Prof. \\
\hline Experience & 9 years & 8 years & 11 years & 11 years & 11 years & 15 years \\
\hline Interest & Teaching \& Literature & Literature & Literature & Linguistics & TEFLM \& ETE & Translation \\
\hline Major & Literature & Literature & ELL & Literature & TEFLM & Translation \\
\hline Score/Percentage & 94.14 & 91.904 & 92.162 & 92.744 & 95.02 & 91.838 \\
\hline University/Level & SYSU/Key & SCNU/Key & SCNU/Key & GXNU/Other & HNNU/Other & JNU/Key \\
\hline Award & Provincial & No & No & Provincial & No & No \\
\hline
\end{tabular}

Notes:

TEFLM \& ETE= TEFL methodology and English teacher education

Position $=$ professional position title

Experience $=$ years of teaching the College English course

Interest $=$ academic and teaching research interests/directions/areas

Degree $=$ the highest degree obtained

Major $=$ major of the highest degree

Score $=$ the latest score by students on classroom teaching at the end of term

University $=$ the university where the highest degree was awarded

Award $=$ award for College English teaching

$\mathrm{ELL}=$ English language and literature

$\mathrm{SCNU}=$ South China Normal University

GXNU= Guangxi Normal University

$\mathrm{HNNU}=$ Hainan Normal University

$\mathrm{JNU}=$ Jinan University

SYSU $=$ Sun Yat-Sen University 


\subsection{The Analysis of Classroom Pedagogical Tasks}

Han [15] pointed out four important characteristics of classroom pedagogical tasks, namely, reasonability, practicality, validity, and flexibility. In this research, the reasonability, practicality, validity, and flexibility of classroom pedagogical tasks were analyzed. This was done because the reasonability and practicality of a pedagogical task are usually two important criteria for evaluating the effects of teachers' lesson planning, and the validity and flexibility of a pedagogical task are two important criteria for evaluating the effect of teachers' interactive classroom decision-making [15].

Reasonability: According to Han [15], reasonability means evaluating whether the tasks teachers design meet with the curricular objectives and content, and students' basic needs, which include students' general interests, fundamental ability, and common learning methods to ensure that most students can basically achieve the curricular objectives.

Practicality: Han [15] defined practicality as the evaluation of whether the objective or difficulty of the tasks that teachers design meet with students' actual abilities. On the one hand, tasks should not be too difficult for students to do, but on the other hand, tasks should not be too easy because students should be challenged in terms of language skills, strategies, and other techniques.

Validity: Validity means evaluating whether the standards of classroom teaching have been reached, which means whether the task process planned by teachers is basically consistent with students' process of actual learning and thinking. It includes two major categories, which are both discussed in the data analysis: the validity of classroom management strategies and the validity of classroom organization strategies [15]. Both of these can reflect teachers' views on teaching.

Validity of Classroom Management: The validity of classroom management strategies include whether the task process, pace, time, and speed are reasonable, and whether the monitoring of the task process and the assessment of task results are effective. If they are not reasonable or effective, the teacher is still far from the advancing view on teaching.

Validity of Classroom Organization: The validity of classroom organization strategies include whether the distribution of tasks and the combination of students in a task are reasonable, and whether students' emotions, thinking, and ways of communication are positive. If they are reasonable and positive, the teacher is close to the advancing view on teaching.

Flexibility: Flexibility means evaluating teachers' adjustments to the changing classroom environment based on the actual conditions of the tasks' accomplishment, including within-task adjustment and after-task adjustment [15]. Thus, in the data analysis of this research, the flexibility of classroom pedagogical tasks is discussed from the following three perspectives: adjusting for students, adjusting for tasks, and adjusting for the classroom.
Adjusting for students: Adjusting for students includes the adjustment of students' emotions, utterances, and thinking. If the teacher is able to adjust all these properly in his or her classroom teaching practice, he or she might hold an advancing view on teaching.

Adjusting for tasks: This includes the adjustment of task difficulty, process, and methods, and adjusting future task objectives, content, and methods. If a teacher cannot adjust these accordingly in his or her daily classroom teaching, this teacher has still not reached the level of the advancing view on teaching.

Adjusting for the classroom: The adjustment of student combination forms and their relationships, and the adjustment of teaching materials and teaching aids, all belong to adjusting for the classroom. More vivid examples of this can be found in the data analysis.

\section{Data Analysis: A Sample (Part of Entire Analysis) Is Below Owing to Word Limit Requirement}

The Analysis of Classroom Pedagogical Tasks: At the end of the last century and the beginning of this one, the foreign language education field experienced a re-recognition of classroom teaching [26, 12, 37, 39, 27]. As the main process of teachers' social practice and professional development, teaching has attracted scholars' full attention. An extensive number of educators have developed a general consensus that more attention should be paid to classroom teaching events (also regarded as pedagogical tasks) and that a better understanding of these events is important [36].

Based on the analytical framework outlined previously, the observed classroom teaching pedagogical tasks of teachers in this study was analyzed under the following sub-titles: the reasonability of classroom pedagogical tasks, the practicality of classroom pedagogical tasks, the validity of classroom pedagogical tasks (which includes task management and task organization), and the flexibility of classroom pedagogical tasks (which includes managing students, controlling tasks, and organizing the classroom). This analysis of the teachers' PCK was based on their pedagogical tasks as observed in their classroom teaching, so the data was largely dependent on participatory classroom teaching observation with interviews and stimulated recall used where necessary as supplementary evidence.

Validity of Classroom Pedagogical Tasks: Validity means whether the planned task process is consistent with the students' actual learning. It includes classroom management and classroom organization. This section will discuss the validity of the pedagogical tasks in the observed lessons of six teachers: Wei, Xie, Liu, Ding, Deng, and Yang.

Classroom Management: Classroom management includes the teacher's strategies of language, communication, questioning, and guidance used to ensure that the process, 
pace, time, and speed of classroom tasks are reasonable; it also includes whether the monitoring of task process and the assessment of task results are effective. Mainly based on the in-classroom observation data, the analysis in Tables 4 to 7 is generally presented in a format that facilitates comparison and contrast among different participants.

Table 4. Teachers' Language Strategies.

\begin{tabular}{ll}
\hline Teacher (s) & Language Strategy \\
\hline Wei & The teacher spoke in English when interacting with her students with some Chinese from time to time for instruction and explanation. \\
Tie & $\begin{array}{l}\text { The teacher kept speaking English with her students, though her speed of speaking English was quite fast. The exception was the last part of } \\
\text { the lesson, when she used a lot of Chinese to teach the students the general structure of the text. } \\
\text { The teacher spoke English gently to communicate with his students in a polite way. }\end{array}$ \\
Ding & $\begin{array}{l}\text { This teacher spoke clear English to communicate with the students throughout the lesson. } \\
\text { The teacher spoke fluent English to communicate with her students most of the class time with some Chinese Putonghua used to comment } \\
\text { on the students' interviews, explain the listening comprehension material, and give the instructions for the last speaking activity. } \\
\text { Throughout the lesson, the teacher spoke English to communicate with her students with lots of Chinese for instruction and explanation. } \\
\text { Yang }\end{array}$ \\
\hline
\end{tabular}

Table 5. Teachers' Communication Strategies.

\begin{tabular}{ll}
\hline Teacher (s) & Communication Strategy \\
\hline Wei & $\begin{array}{l}\text { The teacher communicated with her students not only in class as a facilitator but also before class to prepare for the groups of students' in-class } \\
\text { presentations. }\end{array}$ \\
Xie & Few students responded to the teacher's questions. \\
Liu & The teacher not only talked with the whole class but also supported individual students when they discussed in pairs. \\
Ding & $\begin{array}{l}\text { The teacher not only communicated with all the students when they discussed together at each stage of the lesson but also went to the } \\
\text { individual groups to give support when the students did group work. }\end{array}$ \\
The teacher in this lesson was able to communicate with her students well. Usually, the teacher posed questions to all the students and waited \\
for students' responses. She then repeated some effective answers in order to arouse the other students' attention and check their understanding \\
as well. \\
The teacher communicated with her students formally without much content. She focused on the form of communication (like Q \& A) with the \\
students but not on what to communicate (such as the real significance of the communication); the students usually interacted with the teacher \\
by using very simple words (yes, no, good.).
\end{tabular}

Table 6. Teachers' Questioning Strategies.

\begin{tabular}{ll}
\hline Teacher (s) & Questioning Strategy \\
\hline Wei & $\begin{array}{l}\text { Student presenters posed more questions in the in-class discussion than the teacher did. The questions were mainly raised by presenter students } \\
\text { and answered by audience students. }\end{array}$ \\
Xie & $\begin{array}{l}\text { Very often, after posing questions to the students, the teacher looked for immediate answers from the students but did not leave the students } \\
\text { enough time to prepare for their answers. }\end{array}$ \\
Liu & Not many students responded to the teacher's questions because the teacher was not attention-getting enough when posing questions. \\
Ding & The teacher seldom called on individual students to answer particular questions but mainly raised public questions for all the students to think \\
Deng & about. \\
Yang & The teacher frequently used yes-no questions so that the students' responses were difficult to explore.
\end{tabular}

Table 7. Teachers' Guiding Strategies.

\begin{tabular}{ll}
\hline Teacher (s) & Guiding Strategy \\
\hline Wei & $\begin{array}{l}\text { Before class, the teacher coached the students to prepare for the in-class presentations and, in class, the presenter students led the other } \\
\text { students to have a deeper understanding of the topic with their presentations. }\end{array}$ \\
It was a guiding process when the teacher taught the students how to grasp the general structure of the text, but the teacher conducted this \\
mainly through a monologue almost without interaction with her students. \\
Tiu
\end{tabular}

Interview Extract (Teacher Yang): In the first years of my teaching, I tried to speak English with my students in class. At that time, I taught the slow classes. That means the English language proficiency of the students in those classes was not high. Though some of them could understand my English, lots of them couldn't. I wanted to care for everyone in my class, so after speaking English first, I then translated my English sentences into Chinese. In this way, lots of time in class was 
wasted on language translation. What's more, I felt upset when my students couldn't understand my English. Therefore, after a period of time, I felt lazy about doing the translation and directly spoke Chinese in class when I wanted to express something difficult or complicated, leaving the simple things in English.

The attitudes of students and teachers are interdependent. Say, for example, if students are unmotivated to learn in class, their negative mood will definitely influence the teacher, and maybe she will no longer feel interest in teaching. Teacher Yang did not want to feel let down by her students limited English language proficiency. She also said that she was too lazy to translate from English into Chinese, so she preferred to speak Chinese directly. This implies that Yang was concerned with herself more than with the students. The above excerpt from her interview transcript also suggests that she held a relatively distrustful attitude towards her students' College English learning since she did not trust them to be able to understand her English in class. The following extract from teacher Yang's interview transcription also shows this point of view:

Interview Extract (Teacher Yang): It is difficult for a teacher to help students re-obtain their courage and confidence, as each student has shaped his or her own personality and values with various types of education at home. It would be a challenge for a teacher who has one or two classes in a week to help drive out values which have been developed over decades. What a teacher can do is to encourage and praise the students and pass on some positive energy. In this way, the student will be activated and engage with English learning. But, after class, their active attitudes about English study may disappear, which cannot be controlled by the teacher. In addition, even if the personal charms of a teacher help enhance students' courage and confidence, it won't be a long journey for students to get back into their old scared-of-English learning routine when this special teacher does not teach them anymore. Thus, this question is self-contradictory. Students will not learn well if they always rely on a teacher's assistance to get learning courage and confidence or, in other words, if they rely on outer forces but not themselves. What teachers can do is to spread a positive view of life, but ultimately it is students business to accept or implement it or not.

\section{Results and Discussion}

As discussed in the literature review, teachers' views on knowledge are concentrated in declarative, procedural, and strategic views. The above analysis yielded evidence to suggest that the participant teachers' views on knowledge probably were not well rounded. Though different types of teacher knowledge (declarative, procedural, and strategic) were shown in the data, the analysis also showed that the participants' knowledge structures needed improvement.

The teachers were all qualified based on their subject matter knowledge, but some teachers were not clear about teaching methodology and related theories. For example, teacher Ding did not really understand task-based learning, although she did use tasks in her College English teaching. This is a good example that supports PCK's characteristic of being hidden, as [15] has argued.

Some teachers seemed somewhat unskillful in communicating with students at the pre-, in- and post-class stages, such as teacher Xie, who sometimes did not communicate with her students to check their understanding during text structure analysis in her classroom teaching. Some teachers seemed not especially good at planning lessons or managing classes to meet students' needs, such as teacher Yang, whose lesson plan only included drilling students' test skills, which was probably not the students' actual need.

Some teachers seemed relatively inexperienced in pedagogical reasoning or decision-making. For example, teacher Deng met obstacles to organizing her students to do pair work. Decision-making includes both pre- and in-class decision-making [3], but based on the data analysis in this study, the participant teachers often cared more about pre-class decision-making than in-class decision-making. This means that the teachers were probably less skilled at strategic knowledge than at declarative and procedural knowledge.

Some teachers seemed to have only a vague picture in their minds of educational contexts, ends, purposes, and values. For instance, teacher Yang misunderstood the purpose of the College English course. She seemed to assume that the course was mainly intended to help students pass tests; in fact, the course requirements showed that it was aimed to help students improve their comprehensive English language ability.

Some teachers' personal theories were probably out-of-date and this made it difficult for them to keep up with the needs of their students' development in a modern society. This included teacher Xie, who felt that knowledge could be imparted to her students through text structure analysis. This analysis has shown that, in this study, most teachers lacked comprehensive views on knowledge; in particular, the participants' strategic knowledge needed enormous improvement.

\section{Conclusion}

In terms of views on knowledge (one aspect of PCK), the results of the data analysis in this study revealed that the participant teachers were generally experienced in their use of declarative knowledge, but possibly unskilled in their use of strategic knowledge. To summarize, views on knowledge encompasses teachers' creative ways of thinking and their personal understanding of the discipline of teaching. It is the teachers' ability to endow declarative knowledge with personal significance. Declarative knowledge is objective to everybody; teachers make full use of their personal teaching ability to transfer such knowledge to their students, and this transfer ability by teachers can result in students' different learning outcomes. Views on knowledge include teachers' personal wisdom that transforms procedural knowledge (such as teaching skills) into strategic knowledge (the ability to solve problems in classroom teaching practice). It entails teachers' constant updating and development of their personal 
pedagogical knowledge in the teaching practice of particular subject matter.

\section{Implications}

Teacher Development: What I learned about teachers' use of declarative, procedural, and strategic knowledge hopefully can help others. Changes should be made to teacher professional development to correct the imbalance I found in the types of knowledge teachers use. Zhou [44] summarized the factors influencing teachers' professional development in her presentation "Professional Development through Learning Communities in the Early Years of ELT Practice in China," delivered at the fifth National Academic Conference of Foreign Language Teachers' Education and Development at Guangdong University of Foreign Studies in Guangzhou. She said, "It has been found that the greatest impetus for professional development comes from individual practices through active involvement in learning communities among teachers and between teachers and students in the classroom." Other factors (like teachers' full commitment to the cause and strong motivation for self-improvement) influencing teachers' professional development were also found in the study.

Various supports should be given to teachers to inspire their willingness [42], which is the basis for their hard work and views on knowledge (PCK) development. This was shown in the interview with teacher Xie. She explained that her willingness to teach was impacted by many objective factors. For example, when she graduated from university, she spared no effort to engage in English teaching. Her students' learning achievements were very good at that time, but leaders attached little importance to her class as well as to her efforts. What was worse, in the following school year, she needed some support but nobody responded, which really made her awfully disappointed. She did not receive fair treatment corresponding to her efforts, possibly because she was a new to the organization, which greatly decreased her teaching enthusiasm.

\section{Research Limitations: Subjectivity}

In this research, both the participant teachers and I were subjective to some degree from time to time because subjectivity is inevitable in engagement with a world in which meanings and realities are constructed and not just discovered [8]. Therefore, I used data triangulation to control the degree of subjectivity. That means I tried to use evidence from one source of data to support the conclusions drawn from another source of data in the data analysis.

\section{Acknowledgements}

I thank my daughter from the bottom of my heart for providing an emotional anchor for me during the writing process of this article.

\section{References}

[1] Adams, J. E. (2000). Taking charge of curriculum. Columbia University Press.

[2] Ball, D. L., Thames, M. H., \& Phelps, G. (2008). Content knowledge for teaching: What makes it special? Journal of Teacher Education, 59(5), 389-407.

[3] Bao, Y. \& Tang, Z. (2014). The conceptual criticism and development of Pedagogical Content Knowledge. Education Science, 30(6), 39-44.

[4] Creswell, J. W. (2007). Qualitative inquiry \& research design: Choosing among five approaches. Sage.

[5] Danuse, N. (2011). Researching science teacher pedagogical content knowledge. Problems of Education in the $21^{\text {st }}$ Century. $35,104-118$.

[6] Duff, P. (2008). Case study research in applied linguistics. Erlbaum.

[7] Elbaz, F. (1983). Teacher thinking: A study of practical knowledge. Nichols.

[8] Fernandez, L. M. (2013). Beyond La Nina, La Pinta, and La Santa Maria: The invention and mental mapping of the New World. Social Education, 77, 7-13.

[9] Fernandez, A. N. (2014, December 9). Crossing the border to kindergarten. Education Week.

[10] Freeman, D. \& Richards, J. C. (1996). Teacher learning in language teaching. Cambridge University Press.

[11] Grossman, P. L. (1989). A study in contrast: Sources of PCK for secondary English. Journal of Teacher Education, 40 (5), 24-31.

[12] Grossman, P. L. (1990). The making of a teacher: Teacher knowledge and teacher education. Teachers College Press.

[13] Han, G. (2011). Constructing PCK in EFL teachers. Shanghai Foreign Language Education Press.

[14] Li, W. (2012). The core connotation analysis of Pedagogical Content Knowledge. Journal of Southwest University: Philosophy and Social Science, 38 (1), 26-31.

[15] Liu, S. (2013). A general overview of Pedagogical Content Knowledge. Data of Culture and Education, 34, 155-156.

[16] Liu, X. (2010). A general overview of Pedagogical Content Knowledge in China and the enlightenment of teacher training. Journal of Junior Mathematics: Junior Middle School Edition, $12,10-13$.

[17] Louis, C., Lawrence, M. \& Keith, M. (Eds.). (2007). Research methods in education ( $6^{\text {th }}$ ed.). Routledge.

[18] M. C. Clark, \& P. Peterson. (1993). Teachers' thought processes. Teacher's thought processes. Yamazaki Laboratory of educational psychology, Hokkaido University of education, Hakodate.

[19] Merriam, S. B. (1998). Qualitative research and case study applications in education. Jossey-Bass.

[20] Merriam, S. B. (2001). Qualitative research and case study applications in education. Jossey-Bass. 
[21] Merriam, S. B. (2002). Introduction to qualitative research. In S. B. Merriam \& Associates (Eds.), Qualitative research in practice: Examples for discussion and analysis. Jossey-Bass.

[22] Pi, L. S. (2000). Teaching design. Higher Education Press.

[23] Richards, J. C. (1998). Beyond training. Cambridge University Press.

[24] Roberts, D. A. (2000). Achieving scientific literacy: from purposes to practices. Science Education, 84(1), 123-127.

[25] Russell, T. L. \& Munby, H. (1991). Reframing: The role of experience in developing teachers' professional knowledge. In D. A Schön (Ed.), The reflective turn (pp. 164-187). Teachers College Press.

[26] Schön, D. A. (1983). The reflective practitioner: How professionals think in action. Temple.

[27] Seliger, H. W. \& Shohamy, E. (1989). Second language research methods. Oxford University Press.

[28] Shulman, L. S. (1986). Those who understand: Knowledge growth in teaching. Educational Researcher, 15 (2), 4-14.

[29] Shulman, L. (1987). Knowledge and teaching. Harvard Educational Review, 57.

[30] Stake, R. E. (1995). The art of case study research. Sage.

[31] Sun, T. (2014). Constructing research based on comprehensible Pedagogical Content Knowledge. Teaching Monthly (Middle School Edition) Teaching Reference, 8, 45-48.

[32] Talanquer, V. (2004). Formación docente: qué conocimiento distingue a los buenos maestros de química? educación química.

[33] Tsui, A. B. M. (2003). Understanding expertise in teaching: Case studies of ESL teachers. Cambridge University Press.

[34] Wallace, M. J. (1991). Training foreign language teachers. Cambridge University Press.

[35] Walsh, S. (2006). Investigating classroom discourse. Routledge.

[36] Woods, D. (1996). Teacher cognition in language teaching. Cambridge University Press.

[37] Wu, Y. A. (2005). Study the qualities of excellent FL teachers. Foreign language teaching and research (3).

[38] Xia, J. (2007). The challenges for teachers of college English: Teacher development issues and strategies. Foreign Languages in China, 4 (2), 4-6.

[39] Xie, S. \& Ma, Y. (2013). The development of study in Pedagogical Content Knowledge: On the enlightenment to teacher education study in China. Modern Education Management, 6, 56-61.

[40] Ye, H. (2007). Developing of a knowledge base for the teaching profession. CELEA Journal (Bimonthly). 30 (4), 85-98.

[41] Zhou, Y. (2013). "Professional Development through Learning Communities in the Early Years of ELT Practice in China," presentation delivered at the fifth National Academic Conference of Foreign Language Teachers' Education and Development at Guangdong University of Foreign Studies in Guangzhou. 